\title{
Herbicide residues in sugar beet roots
}

\section{Pozostałości herbicydów w korzeniach buraka cukrowego}

\author{
Mariusz Kucharski, Jerzy Sadowski
}

\section{Summary}

The aim of the studies was to evaluate the herbicidal contaminations in sugar beet roots. Monitoring tests were carried out during 2010-2012 on sugar beet plantation located in South-Western Poland. The samples of sugar beet roots were collected at harvest time. The determination of fenmedipham, desmedipham, ethofumesate, metamitrom, chloridazon and lenacil residues were conducted using the high performance liquid chromatography with ultraviolet detection (HPLC/UV - high-performance liquid chromatography with ultraviolet). Monitoring studies showed that $56 \%$ of tested root samples did not contain detectable residues of tested herbicides. The residues of herbicide determined in $44 \%$ of samples ranged from 0.0004 to $0.0096 \mathrm{mg} / \mathrm{kg}$. The concentration of residues detected in tested root samples did not exceed the maximum residue levels (MRLs).

Key words: herbicide; sugar beet; residues monitoring; MRLs

\section{Streszczenie}

Celem badań była ocena zanieczyszczeń herbicydowych w korzeniach buraka cukrowego. Badania monitoringowe prowadzono w latach 2010-2012 na plantacjach buraka cukrowego, zlokalizowanych w południowo-zachodniej Polsce. Próbki korzeni do analiz pobierano przed zbiorem buraka. Oznaczanie pozostałości: fenmedifamu, desmedifamu, etofumesatu, metamitronu, chlorydazonu i lenacylu wykonano techniką chromatografii cieczowej (HPLC/UV - high-performance liquid chromatography with ultraviolet). Na podstawie przeprowadzonych badań monitoringowych można stwierdzić, że w 56\% próbek korzeni nie stwierdzono oznaczalnych pozostałości herbicydów. Pozostałości wykryte w $44 \%$ próbek wahały się w zakresie 0,0004-0,0096 mg/kg. W analizowanych próbkach korzeni buraka nie stwierdzono pozostałości, których stężenie przekraczało najwyższe dopuszczalne poziomy pozostałości (NDP).

Słowa kluczowe: herbicyd; burak cukrowy; monitoring pozostałości; NDP

Instytut Uprawy Nawożenia i Gleboznawstwa - Państwowy Instytut Badawczy

Zakład Herbologii i Technik Uprawy Roli

Orzechowa 61, 50-540 Wrocław

m.kucharski@iung.wroclaw.pl 


\section{Wstęp / Introduction}

Konieczność zabezpieczenia życia i zdrowia ludzi oraz ochrony środowiska, wymusza ciagłe zmiany przepisów prawnych związanych $\mathrm{z}$ wytwarzaniem odpowiedniej jakości produktów rolnych, $\mathrm{z}$ zachowaniem wysokiej dbałości o stan środowiska. Nowe strategie w ochronie roślin, wprowadzane po wejściu w życie Dyrektywy 2009/128/WE, zmierzające do racjonalnego ograniczenia stosowania środków ochrony roślin umożliwiają wypracowanie, dla lokalnych warunków, właściwych metod pozwalających na zmniejszenie zużycia środków chemicznych, $\quad \mathrm{z}$ jednoczesnym zachowaniem pożądanej skuteczności działania.

Burak cukrowy należy do upraw, dla ochrony której niezbędne jest stosowanie chemicznych środków ochrony roślin. Asortyment herbicydów stosowanych w ochronie buraka cukrowego jest niezmienny od blisko czterdziestu lat. Poszukiwanie rozwiązań proekologicznych ukierunkowane zostało $\mathrm{w}$ stronę zmian $\mathrm{w}$ technice i sposobie aplikacji środków chwastobójczych, polegających na: aplikacji herbicydów w systemie dawek dzielonych, stosowaniu programu „mikrodawek”, wykorzystaniu właściwości substancji wspomagających (adiuwantów) oraz aplikacji herbicydów wieloskładnikowych (Kucharski i wsp. 2008; Wujek i wsp. 2012).

Badania pozostałości środków ochrony roślin umożliwiają ocenę wpływu stosowanych substancji na środowisko i zdrowie ludzi (Łozowicka i wsp. 2012a; Nowacka i wsp. 2012a; Wujek i wsp. 2012). Ponadto wieloletnie badania monitoringowe umożliwiają analize skutków wprowadzanych zmian i wybór najlepszych metod minimalizujących ryzyko wynikające ze stosowania chemicznych środków ochrony roślin.

Celem pracy była analiza zanieczyszczeń herbicydowych w korzeniu buraka cukrowego na podstawie badań monitoringowych plantacji buraka uprawianego na polach województwa dolnośląskiego i opolskiego.

\section{Materiały i metody / Materials and methods}

Badania prowadzono w latach 2010-2012, na plantacjach produkcyjnych buraka cukrowego. $\mathrm{W}$ trzech sezonach wegetacyjnych, krótko przed zbiorem, pobrano próbki korzeni buraka z 53 plantacji (42 - województwo dolnośląskie, 11 - województwo opolskie). Na podstawie wywiadu, przeprowadzonego $\mathrm{z}$ właścicielami pól, ustalono że w większości przypadków przedplonem dla buraka były zboża (głównie pszenica i jęczmień ozimy), plantacje zakładane były na dobrych glebach klasy II i IIIa $(\mathrm{pH}=$ $\left.6,0-6,5, \mathrm{C}_{\text {org }}=1,8-2,4 \%\right)$. Wielkość plantacji buraka była zróżnicowana i wahała się $w$ granicach od 2 do 12 hektarów. Wytypowane plantacje zostały objęte nadzorem umożliwiającym kontrolę poprawności wykonywanych zabiegów herbicydowych. Rolnicy stosowali środki zawierające: fenmedifam, desmedifam, etofumesat, metamitron, lenacyl i chlorydazon. Aplikacja herbicydów prowadzona była $w$ terminach i dawkach zgodnych $\mathrm{z}$ zaleceniami producentów środków. Herbicydy stosowane były w różnych, ogólnie przyjętych systemach: łączenie zabiegów przed- i powschodowych, dawki dzielone (3-5 zabiegów powschodowych) oraz aplikacja przedwschodowa i 2-3-krotny zabieg powschodowy.

W pobranych próbkach korzeni buraka cukrowego przeprowadzono badania umożliwiające wykrycie pozostałości wszystkich wymienionych powyżej substancji czynnych (s.cz.) herbicydów. Analizę pozostałości wykonano zgodnie $\mathrm{z}$ procedurami opracowanymi $\mathrm{w}$ Instytucie Uprawy Nawożenia i Gleboznawstwa - Państwowym Instytucie Badawczym (Kucharski 2007; Kucharski i wsp. 2011, 2012a, b). Procedury analityczne składaja się z trzech podstawowych etapów obejmujących: (1) ekstrakcję s.cz. herbicydu z matrycy próbki (jako ekstrahenty stosowano: chlorek metylenu, metanol, aceton), (2) oczyszczanie ekstraktów (w tym etapie stosowano reekstrakcję chlorkiem metylenu oraz oczyszczanie na kolumnach SPE (Solid Phase Extraction) z wypełnieniem: octadecyl C18 $(0,5 \mathrm{~g}, 40 \mu \mathrm{m})$ i silicagel $(0,5 \mathrm{~g}, 50 \mu \mathrm{m})$ (Bakerbond $^{\circledR}$, J.T. Baker ${ }^{\mathbb{B}}$, Philipsburg, NJ, USA), (3) końcowe oznaczenie, wykonano na chromatografie cieczowym HPLC/UV (high-performance liquid chromatography with ultraviolet) (Shimadzu ${ }^{\circledR}$, Tokyo, Japan). W skład zestawu chromatograficznego wchodzą: pompa LC-10AT, odgazowywacz DGU-4A, piec kolumny CTO10AS, system kontroli SCL-10A oraz detektor UV SPD10A. Każdą z próbek analizowano 3-krotnie. Różnice pomiędzy uzyskanymi wynikami analiz nie przekraczały $7 \%$ w stosunku do wartości średniej. Granicę oznaczalności oraz średni odzysk metody analitycznej dla poszczególnych s.cz. zamieszczono $\mathrm{w}$ tabeli 1 .

Tabela 1. Średni odzysk i granica oznaczalności metody analitycznej dla badanych s.cz. herbicydów

Table 1. The average recoveries and quantification limits of the analytical method for tested active substance of herbicide

\begin{tabular}{l|c|c}
\hline $\begin{array}{c}\text { Substancja czynna } \\
\text { Active substance }\end{array}$ & $\begin{array}{c}\text { Średni odzysk } \\
\text { Average recovery } \\
{[\%]}\end{array}$ & $\begin{array}{c}\text { Granica oznaczalności } \\
\text { Limit of quantification } \\
{[\mathrm{mg} / \mathrm{kg}]}\end{array}$ \\
\hline Phenmedipham & 92 & 0,0001 \\
\hline Desmedipham & 88 & 0,0001 \\
\hline Ethofumesate & 78 & 0,0005 \\
\hline Metamitron & 85 & 0,0005 \\
\hline Lenacil & 92 & 0,0005 \\
\hline Chloridazon & 97 & 0,0005 \\
\hline
\end{tabular}

\section{Wyniki i dyskusja / Results and discussion}

W ciagu trzech lat badań wykonano analizę 53 próbek korzeni buraka cukrowego (średnie próby z 53 plantacji). W 18 przypadkach stwierdzono obecność pozostałości badanych substancji (44\% próbek). Biorąc pod uwagę poszczególne s.cz. herbicydów i liczbę próbek korzeni buraka, w których stosowano te środki, można stwierdzić, że najczęściej wykrywano fenmedifam i metamitron (11 i 9 próbek). Pozostałości lenacylu i chlorydazonu stwierdzono w sumie w 5 próbkach (średnio 10,9\% 
Tabela 2. Liczba próbek i zakres wykrywanych pozostałości

Table 2. Number of samples and range of detected residues

\begin{tabular}{l|c|c|c|c}
\hline $\begin{array}{c}\text { Substancja czynna } \\
\text { Active substance }\end{array}$ & $\begin{array}{c}\text { Liczba próbek } \\
\text { Number of samples }\end{array}$ & $\begin{array}{c}\text { Próbki z } \\
\text { pozostałościami } \\
\text { Samples with residues }\end{array}$ & $\begin{array}{c}\text { \% próbek z } \\
\text { pozostałościami } \\
\text { of samples with } \\
\text { residues }\end{array}$ & $\begin{array}{c}\text { Zakres wykrytych } \\
\text { pozostałości } \\
\text { Range of detected residues } \\
{[\mathrm{mg} / \mathrm{kg}]}\end{array}$ \\
\hline Phenmedipham & 51 & 11 & 21,6 & $0,0006-0,0082$ \\
\hline Desmedipham & 46 & 7 & 15,2 & $0,0004-0,0058$ \\
\hline Ethofumesate & 49 & 6 & 12,2 & $0,0005-0,0040$ \\
\hline Metamitron & 43 & 9 & 20,9 & $0,0010-0,0096$ \\
\hline Lenacil & 27 & 2 & 7,4 & $0,0015-0,0026$ \\
\hline Chloridazon & 19 & 3 & 15,8 & $0,0018-0,0068$ \\
\hline
\end{tabular}

badanych próbek) (tab. 2). Jak wspomniano wcześniej, herbicydy stosowane były $\mathrm{w}$ różnych kombinacjach (systemy odchwaszczania buraka cukrowego), które przewidują aplikację kilku s.cz. Z tego powodu w 55\% próbek z pozostałościami stwierdzano obecność więcej niż jednej s.cz. W czterech próbkach korzeni wykryto pozostałości 4 s.cz., w 2 próbkach - 3 s.cz., w 4 próbkach - 2 s.cz. Porównując uzyskane wyniki z wcześniejszymi danymi można stwierdzić, że procentowy udział próbek z pozostałościami zmniejszył się (Kucharski 2003, 2009; Kucharski i Domaradzki 2009). Podobnie wygląda porównanie $\mathrm{w}$ ocenie stężeń wykrywanych pozostałości. W obecnych badaniach zakres stężeń wahał się w przedziale $0,0004-0,0096 \mathrm{mg} / \mathrm{kg}$, natomiast w poprzednich analizach maksymalne pozostałości dochodziły do 0,02 mg/kg (Kucharski 2003, 2009). Obserwowana tendencja spadkowa świadczy o tym, że rolnicy stosują się do zaleceń etykiet środków oraz najnowszych programów ochrony buraka cukrowego. W badaniach porównujących różne systemy chemicznego odchwaszczania buraka cukrowego, jednoznacznie udowodniono, że stosowanie adiuwantów oraz systemu dawek dzielonych (w tym mikrodawek), znacząco ogranicza sumaryczną ilość wprowadzanych do środowiska herbicydów, bez straty poziomu skuteczności chwastobójczej i umożliwia obniżenie stężenia pozostałości tych substancji w glebie i korzeniach buraka, nawet o $30-70 \%$ w porównaniu $\mathrm{z}$ tradycyjnymi zabiegami ochrony roślin stosowanymi w tej uprawie (Kucharski i wsp. 2008; Wujek i wsp. 2012).

$\mathrm{W}$ żadnej $\mathrm{z}$ badanych próbek buraka cukrowego nie stwierdzono pozostałości, których stężenie byłoby zbliżone lub przekraczało najwyższe dopuszczalne poziomy pozostałości (NDP). Dla badanych substancji poziom NDP kształtuje się w granicach $0,1-0,5 \mathrm{mg} / \mathrm{kg}$ (Regulation 396/2005), a maksymalne wartości uzyskane w badaniach nie przekraczały $0,01 \mathrm{mg} / \mathrm{kg}$.

Przedstawione wyniki badań pozostałości s.cz. herbicydów w korzeniach buraka cukrowego wskazują, że stosowanie herbicydów nie stanowi zagrożenia dla ludzi i środowiska rolniczego. Jednak pobrane próbki roślinne pochodziły z pól, na których wszystkie zabiegi agrotechniczne oraz aplikacja herbicydów była kontrolowana i zgodna $z$ zaleceniami. Zdarzają się jednak sporadyczne przypadki przekroczeń wartości dopuszczalnych (NDP), których przyczyną są zwykle: niewiedza rolników, zły stan sprzętu opryskującego, przekraczanie dawki zalecanej, stosowanie środków podrabianych lub przemyślane działanie rolnika, który celowo niszczy plantację licząc na odszkodowanie (Sadowski i Kucharski 2005).

W Polsce, badania monitoringowe pozostałości środków ochrony roślin w płodach rolnych prowadzone są na znacznie szerszą skalę przez Instytut Ochrony Roślin Państwowy Instytut Badawczy w Poznaniu (Łozowicka i wsp. 2012b; Nowacka i wsp. 2012b). Badania te znacząco różnią się metodycznie (zakres badań, liczba próbek i metody analityczne), co uniemożliwia ich porównanie $\mathrm{z}$ materiałem przedstawionym w pracy. Bazując na danych pochodzących z: Europejskiego Urzędu ds. Bezpieczeństwa Żywności (EFSA - European Food Safety Authority) (EFSA Scientific Report 2010), monitoringu wód powierzchniowych i gruntowych południowozachodniej Polski (Sadowski i Kucharski 2003; Sadowski i wsp. 2009) oraz obserwacji i badań własnych (Kucharski 2003), nie stwierdzono negatywnego wpływu stosowanych herbicydów na rośliny następcze, zdrowie ludzi oraz obecność pozostałości tych substancji w wodach powierzchniowych i gruntowych terenów rolniczych.

\section{Wnioski / Conclusions}

1. $\mathrm{W}$ próbkach korzeni pochodzących $\mathrm{z}$ plantacji buraka cukrowego zlokalizowanych na polach południowozachodniej Polski wykryto pozostałości: fenmedifamu, desmedifamu, etofumesatu, lenacylu, metamitronu i chlorydazonu.

2. W żadnej $\mathrm{z}$ badanych próbek buraka cukrowego nie stwierdzono pozostałości, których stężenie byłoby zbliżone lub przekraczało najwyższe dopuszczalne poziomy pozostałości (NDP).

3. Przedstawione wyniki badań pozostałości s.cz. herbicydów w korzeniach buraka cukrowego wskazuja, że stosowanie herbicydów zgodnie $\mathrm{z}$ zaleceniami producentów środków ochrony roślin, jak również zasadami dobrej praktyki rolniczej, nie stanowi zagrożenia dla ludzi i środowiska rolniczego.

Badania wykonano w ramach zadania 2.6 Programu Wieloletniego Instytutu Uprawy Nawożenia i Gleboznawstwa - Państwowego Instytutu Badawczego w Puławach. 


\section{Literatura / References}

Dyrektywa UE 2009/128/WE z dnia 21 października 2009, ustalająca ramy wspólnego działania na rzecz zrównoważonego stosowania pestycydów. Dz. U. UE, L 309/71 z dnia 24 listopada 2009, 71 ss.

EFSA Scientific Report 2010. The 2010 European Union report on pesticide residues in food. http://www.efsa.europa.eu/en/efsajournal/ pub/ [Accessed: 20.09.2013].

Kucharski M. 2003. Influence of herbicide and adjuvant application on residues in soil and plant of sugar beet. J. Plant Prot. Res. 43 (3): $225-232$.

Kucharski M. 2007. Impact of adjuvants on: phenmedipham, desmedipham and ethofumesate residues in soil and plant. Pestycydy/Pesticides (3-4)/2007: 53-59.

Kucharski M. 2009. Changes in application system - influence on herbicides residue in soil and sugar beet roots. J. Plant Prot. Res. 49 (4): 421-425.

Kucharski M., Domaradzki K. 2009. Pozostałości herbicydów w wybranych roślinach uprawnych - badania z lat 2000-2008. Fragm. Agron. 26 (4): 74-80.

Kucharski M., Domaradzki K., Wujek B. 2008. Micro-rates of herbicides used in sugar beet crop - influence on herbicide residues level in roots and soil. Pestycydy/Pesticides (3-4)/2008: 63-69.

Kucharski M., Sadowski J., Domaradzki K. 2012a. Degradation rate of chloridazon in soil as influenced by adjuvants. J. Plant Prot. Res. 52 (1): $147-150$.

Kucharski M., Sadowski J., Trajdos J. 2012b. Rozkład metamitronu w glebie w zależności od formulacji i sposobu aplikacji herbicydu. [Metamitron decay in soil depending on herbicide formulation and application method]. Prog. Plant Prot./Post. Ochr. Roślin 52 (1): $137-140$.

Kucharski M., Sadowski J., Wujek B., Trajdos J. 2011. Influence of adjuvant addition on lenacil residues in plant and soil. Pol. J. Agron. 5: 39-49.

Łozowicka B., Jankowska M., Kaczyński P. 2012a. Pesticide residues in Brassica vegetables and exposure assessment of consumer. Food Control 25 (2): 561-575.

Łozowicka B., Miciński J., Zwierzchowski G., Kowalski I.M., Szarek J. 2012b. Monitoring study of pesticide residues in cereals and foodstuff from Poland. Pol. J. Environ. Stud. 21 (6): 1703-1712.

Nowacka A., Gnusowski B., Raczkowski M. 2012a. Bezpieczeństwo zdrowotne polskich płodów rolnych w 2010 roku związane z pozostałościami środków ochrony roślin. [Estimation of dietary exposure to pesticide residues in polish crops in 2010]. Prog. Plant Prot./Post. Ochr. Roślin 52 (1): 141-145.

Nowacka A., Gnusowski B., Walorczyk S., Drożdżyński D., Raczkowski M., Hołodyńska A., Frąckowiak D., Wójcik A., Ziółkowski A., Przewoźniak M., Swoboda W., Rzeszutko U., Domańska I., Jurys J., Łozowicka B., Kaczyński P., Rutkowska E., Jankowska M., Hrynko I., Szpyrka E., Rupar J., Rogozińska K., Kurdziel A., Słowik-Borowiec M., Szala J., Szponik M., Michel M. $2012 b$. Pozostałości środków ochrony roślin w płodach rolnych (rok 2011). [Pesticide residues in Polish crops (2011)]. Prog. Plant Prot./Post. Ochr. Roślin 52 (4): 1106-1116.

Regulation (EC) No 396/2005 of 23 February 2005 on maximum residue levels of pesticides in or on food and feed of plant and animal origin and amending Council Directive 91/414/EEC. Official J. European Union, 16.03.2005, L 70: 1-16.

Sadowski J., Kucharski M. 2003. Monitoring of herbicidal pollution in ground and surface water on arable land of South-West Poland. J. Plant Prot. Res. 43 (3): 241-245.

Sadowski J., Kucharski M. 2005. Skutki niewłaściwego, w tym celowego stosowania herbicydów. [Effects of improper use of herbicides including purposeful one]. Prog. Plant Prot./Post. Ochr. Roślin 45 (1): 429-434.

Sadowski J., Kucharski M., Wujek B., Wysocki A. 2009. Multipozostałości herbicydów w wodach powierzchniowych i gruntowych na terenach rolniczych Dolnego Śląska. [Multiresidues of herbicides in surface and groundwater on cultivated terrain of Lower Silesia]. Prog. Plant Prot./Post. Ochr. Roślin 49 (4): 1923-1930.

Wujek B., Kucharski M., Domaradzki K. 2012. Weed control programs in sugar beet (Beta vulgaris L.): Influence on herbicidal residue and yield quality. J. Food Agric. Environ. 10 (3\&4): 606-609. 